\title{
Stakeholder perceptions of a new model of care for medication supply at hospital discharge
}

\author{
Sally Wright, ${ }^{\oplus 1,2}$ Charles W Morecroft, ${ }^{1}$ Rachel Mullen, ${ }^{1}$ Alison B Ewing ${ }^{1,2}$
}

\begin{abstract}
${ }^{1}$ Centre for Pharmacy Innovation, Liverpool John Moores University, Liverpool, UK

${ }^{2}$ Department of Pharmacy, Royal Liverpool and Broadgreen University Hospitals NHS Trust, Liverpool, UK
\end{abstract}

\section{Correspondence to} Dr. SallyWright; s.wright@ ljmu.ac.uk

Received 22 December 2017 Revised 19 March 2018

Accepted 27 March 2018 Published Online First 26 April 2018

EAHP Statement 4: Clinical Pharmacy Services.
Check for updates

To cite: Wright $\mathrm{S}$,

Morecroft CW, Mullen R, et al. Eur J Hosp Pharm 2019:26:268-274.

\begin{abstract}
Objectives Problems relating to patients' medication are common during hospital discharge, often resulting in unnecessary harm to patients and even hospital readmission. To overcome these issues and improve patient discharge, an evidence-based approach was used to develop an innovative model of care for the supply of medication at hospital discharge. The model increases pharmacy involvement, uses community pharmacies in the supply process and encourages patient follow-up after discharge. This study aimed to determine if the proposed new model of care was considered feasible and acceptable by the target population.
\end{abstract}

Methods This formative evaluation involved qualitative interviews and focus groups to explore the opinions of stakeholders involved in delivery or use of the new model of care. A range of stakeholders participated, including a variety of hospital and community-based healthcare professionals as well as expert patients and carers. Thematic analysis of the data was undertaken.

Results The study provided a holistic overview of stakeholder perceptions of the new model of care. Overall, stakeholders were enthusiastic about the new model. Three themes emerged during analysis, providing an informative review of the new model. Themes included: impact, resources required and ensuring safety and quality of the new model of care. Potential issues were identified within each theme along with ideas for overcoming these issues.

Conclusions The new model of care appears to be a positive step towards improving patient discharge from hospital. Future work will involve a pilot of the new model of care using the study findings to assist with implementation.

\section{INTRODUCTION}

National Health Service (NHS) England's mission is to secure high-quality care for all. ${ }^{1}$ Patient discharge from hospital back into the community is an important step in the patient journey requiring high-quality care. To ensure high-quality care at discharge, communication between care settings is essential to provide safe and robust ongoing care. Hospital discharge is complex, involving aspects of both health and social care, and depends on individual patient needs. This paper will focus on the process of medication supply at discharge and transfer of any associated information to healthcare professionals in the community.

Currently, the process of medication supply at discharge begins with the creation of a discharge prescription, commonly referred to as 'To Take Out' (TTO). The TTO is a complete and accurate list of all medications the patient should take after discharge from hospital. A typical discharge process involves a doctor writing the TTO for a patient which is checked by a pharmacist. Any medication needed is dispensed by the hospital pharmacy based on this TTO. The nurse responsible for the patient on the ward will check the medications against the TTO before giving them to the patient. A copy of the TTO is then sent to the patient's general practitioner (GP) within 24 hours of their discharge, along with a copy of the discharge summary containing details of the inpatient episode. Providing a complete and accurate discharge summary aids the transfer of care from hospital into the community and allows the GP to coordinate appropriate ongoing care. ${ }^{2}$ The discharge summary is not routinely provided to other healthcare professionals in the community.

A variety of issues are associated with the current discharge process. Discharging patients from acute NHS hospitals is a time-consuming process, often resulting in patients waiting for medicines and temporarily blocking beds. ${ }^{3}$ Additionally, many older patients experience medication discrepancies after transferring from hospital to home ${ }^{4}$ which can cause unnecessary harm to patients and can result in readmission to hospital. ${ }^{5}$ There are many potential sources of error at discharge, ${ }^{67}$ particularly with regard to the supply of discharge medication and communication between care settings. Factors thought to contribute to medication discrepancies after hospital discharge include: incomplete information on discharge summaries sent to GPs, ${ }^{8-11}$ lack of prompt transfer of information to a patient's $\mathrm{GP}^{8} 91112$ and lack of patient understanding of discharge instructions. ${ }^{8} 913$

Many attempts have been made to improve patient discharge with varied success. Worldwide, several large-scale programmes were designed to improve transitions of care. ${ }^{14-19}$ In the UK, smaller scale interventions have taken place, with few published studies of the findings. Improvement interventions have targeted different aspects of patient discharge. During hospital admission, interventions such as utilising pharmacist prescribers to write discharge prescriptions, ${ }^{3}{ }^{20}$ pre-empting writing discharge prescriptions ${ }^{21}$ and dispensing for discharge ${ }^{8}$ have been used. Other interventions across the interface such as carrying out medication reviews after discharge 2223 and utilising community pharmacists to improve transfer of care ${ }^{24-28}$ have shown some benefit.

\section{Development of a new model of care to improve} patient discharge

Improvement is still required at discharge to ensure high-quality care across the interface and to reduce the problems that impact both patients 
and healthcare providers alike. Consequently, the research team opted for an innovative solution to improve patient discharge and developed a new model of care (MOC) for the supply of medication at discharge, which aimed to provide safe, quality and effective transfer for patients across the hospital-community interface. The research team consisted of a team of pharmacists with backgrounds in primary care, hospital and community pharmacy. Development of the new MOC was evidence based and involved a multistage process. This began with an exploration of the issues with the current discharge process, their causes and potential solutions. Both qualitative and quantitative methods were used to investigate the current discharge process from multiple perspectives. Numerous issues were highlighted with the discharge process. Full details can be seen in two previously published papers. ${ }^{62}$ Key issues highlighted by both pharmacists and patients were: the time delay between informing patients about their discharge and them leaving the hospital, the length of time taken to supply medication for discharge and the quality of patient counselling. Based on these findings and current literature, the MOC was developed and revised until the new MOC for the supply of discharge medication was finalised. This MOC can be seen in figure 1 .

The MOC differs from the current discharge process significantly. The MOC involves a pharmacy-led process within the hospital, which aims to improve collaboration across the interface by sending an electronic copy of the discharge prescription to a community pharmacy of the patient's choice to be dispensed. There are two reasons for this: to reduce the wait for discharge medication in hospital and to promote communication between hospital and community pharmacists. This should prompt patient follow-up by community pharmacists and allow them to provide appropriate patient care after discharge from hospital.

This study involved a formative evaluation of the new MOC, which looked to identify any potential issues and establish the views of relevant stakeholders involved in different aspects of the new MOC. The findings from this formative evaluation were important to facilitate the MOC's success upon implementation.

\section{AIM}

To determine if the proposed new MOC for the supply of medication at hospital discharge was considered feasible and acceptable by stakeholders.

\section{METHOD}

This qualitative study involved semistructured, face-to-face interviews and focus groups with stakeholders. The data collection method chosen was dependent on availability and preference of participants, providing both options increased participation. For example, patient and carer representatives preferred to participate in a focus group. The data collection methods were both suitable to provide detailed, thought-provoking discussions about the MOC with participants and allowed the researcher to probe for more detail where appropriate. A range of stakeholders involved in different aspects of the new MOC were appropriate to identify issues and suggest improvements to different aspects of the MOC. Stakeholders included: potential service users, hospital pharmacists, pharmacy technicians, nursing staff, hospital doctors, community pharmacists and GPs. Participants were drawn from hospital staff in NHS hospitals across Cheshire and Merseyside. Non-hospital-based participants were identified from GP practices, community pharmacies and patients and public involvement groups in the Merseyside area. Participants unfamiliar with any aspect of patient discharge from hospital were excluded, as were patients or carers with no experience of discharge, as their contribution was considered to be limited.

Potential participants were identified via a snowballing sampling method through informal professional networks due to their involvement in the discharge process and invited to participate. Participants were approached either in person or via email as appropriate and were provided with study information. All those who were approached agreed to participate and were included in the study.

A topic guide was developed to meet the study aim which was suitable for use in interviews and focus groups to ensure validity of data. Each session began with an explanation of the MOC by the researcher, with questions from participants to ensure that they were clear about what the MOC involved. Key topics for discussion were based on the new MOC and included: feedback on the new MOC, suggestions for improvement, practical issues and resources required to provide the new MOC. No topics were discussed that any of the participants found distressing. Interviews and focus groups were audio-recorded. Data collection continued until data saturation was achieved.

The audio-recorded interviews and focus groups were transcribed verbatim by the researcher and checked to ensure content and meaning was maintained. All data were anonymised at the transcription stage by removing participant identifiable information. Thematic analysis was carried out using NVivo V.10 software to code transcripts.

LJMU Research Ethics Committee approval (16/PBS/002) was granted on 25 June 2016. A pilot study was undertaken with two pharmacists to verify the recruitment procedure and the topic guide prior to commencing data collection. No significant amendments were required as a result of the pilot and the pilot data were included in the main study.

\section{FINDINGS}

A total of 37 people participated in this study. Of these, 23 were interviewed; the average duration of the interviews was $32 \mathrm{~min}$ (range 19-60 min). The remaining 14 participants participated in two focus groups. Both focus groups contained seven participants from similar backgrounds but with differing levels of experience. The two focus groups lasted 29 and $28 \mathrm{~min}$, respectively. Participant demographics can be seen in table 1 .

Data analysis revealed three main themes, providing a holistic overview of stakeholder perceptions of the new MOC. The salient points from each theme are discussed below with anonymised quotes annotated with the participants' roles for context.

\section{Impact of the new MOC}

Overall, participants anticipated many benefits from the new MOC and highlighted areas that it may impact.

\section{Impact on patient care}

Integrating a pharmacist into the ward team to write discharge prescriptions, counsel and inform patients about their discharge at the point that they are told they can go home was seen as beneficial. Participants agreed that there would likely be an improvement in patient care received, speed of discharge and therefore patient experience.

There will be a massive help in terms of time-saving, bed occupancy and patient journey. The journey will be better as they'll be much happier and can leave the hospital sooner. (Specialist paediatric pharmacist) 


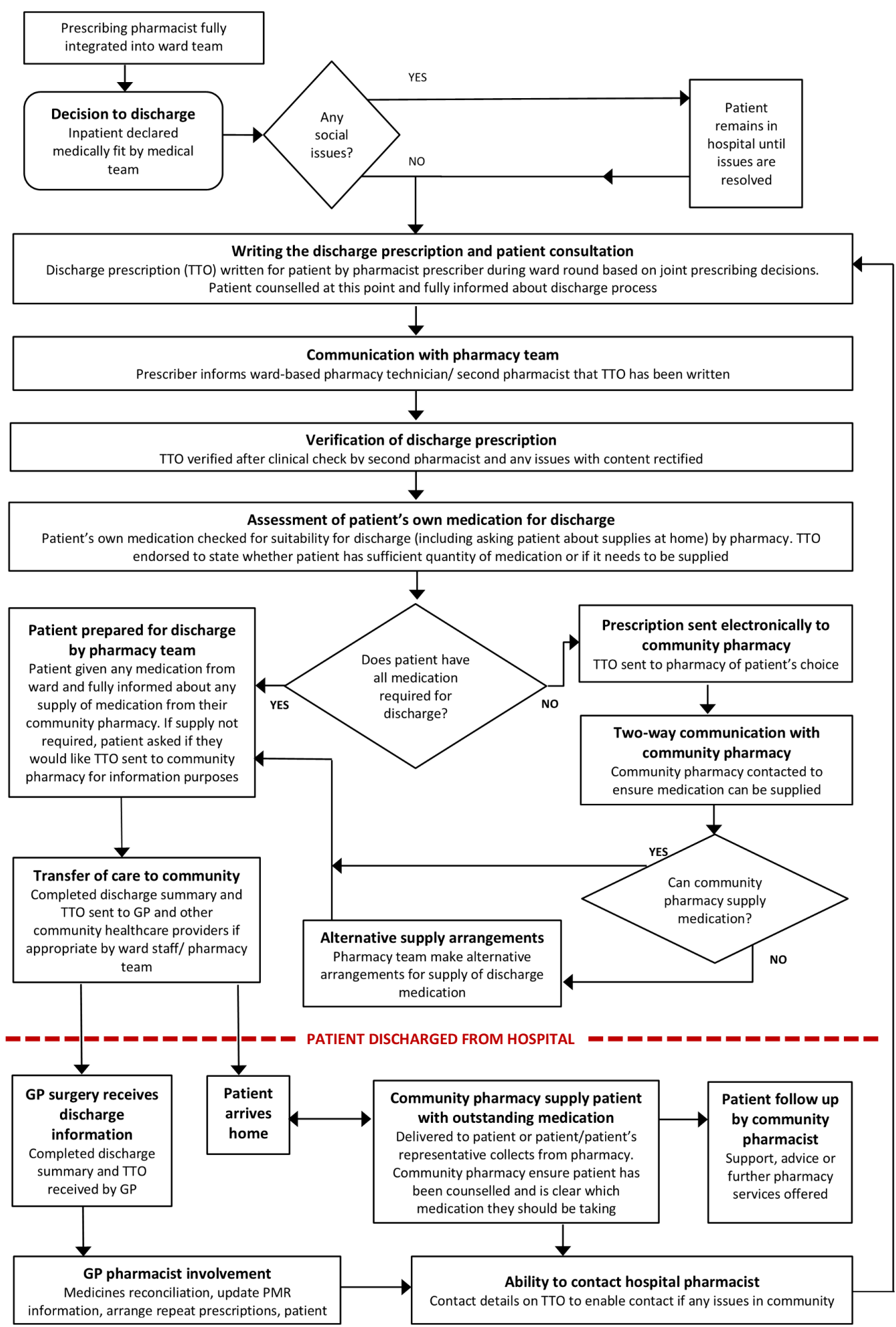

Figure 1 New model of care for the supply of medication at hospital discharge. GP, general practitioner; TTO, To Take Out.

Providing detailed discharge information to the patient's regular community pharmacy was also thought to improve patient care. For patients with existing repeat prescriptions, community pharmacists would be familiar with any changes to the patient's medication and be able to supply the most recent medication rather than medication that may no longer be suitable. This was seen as an additional mechanism of reducing the risk of patient harm as well as reducing medicines waste.
Impact on delays at discharge

Stakeholders agreed that the new MOC would reduce delays to discharge. Ensuring the discharge prescription is written by a prescribing pharmacist at the time of decision to discharge enables the patient to leave the hospital when their discharge prescription is sent to a community pharmacy for dispensing.

Participants also identified two main areas within the new MOC that could potentially delay discharge. First, the logistics of writing 


\begin{tabular}{|c|c|c|}
\hline $\begin{array}{l}\text { Participant } \\
\text { interviews }\end{array}$ & Job role & Place of work \\
\hline 1 & Clinical pharmacy services manager & City centre teaching hospital \\
\hline 2 & General practitioner & GP practice \\
\hline 3 & Consultant pharmacist & City centre teaching hospital \\
\hline 4 & $\begin{array}{l}\text { Independent prescriber hospital } \\
\text { pharmacist }\end{array}$ & City centre teaching hospital \\
\hline 5 & Medicines management pharmacist & City centre teaching hospital \\
\hline 6 & Pharmacist teacher practitioner & $\begin{array}{l}\text { University/city centre teaching } \\
\text { hospital }\end{array}$ \\
\hline 7 & Community pharmacist & City centre community pharmacy \\
\hline 8 & Community pharmacist & Suburban community pharmacy \\
\hline 9 & $\begin{array}{l}\text { Medicines safety and care of the } \\
\text { elderly pharmacist }\end{array}$ & City centre teaching hospital \\
\hline 10 & Rotational hospital pharmacist & City centre teaching hospital \\
\hline 11 & Band 7 haematology pharmacist & City centre teaching hospital \\
\hline 12 & Nurse ward manager & City centre teaching hospital \\
\hline 13 & Senior hospital pharmacist & Large district general hospital \\
\hline 14 & Lead pharmacist for medicine & City centre teaching hospital \\
\hline 15 & $\begin{array}{l}\text { Primary care prescribing } \\
\text { pharmacist }\end{array}$ & Clinical commissioning group \\
\hline 16 & Outpatient dispensing pharmacist & Large teaching hospital \\
\hline 17 & Specialist paediatric pharmacist & Children's hospital \\
\hline 18 & Medical education pharmacist & $\begin{array}{l}\text { University/city centre teaching } \\
\text { hospital }\end{array}$ \\
\hline 19 & Junior doctor, medical specialties & City centre teaching hospital \\
\hline 20 & Junior doctor, surgical trainee & Teaching hospital \\
\hline 21 & Consultant, acute medicine & City centre teaching hospital \\
\hline 22 & General practitioner & GP practice \\
\hline 23 & $\begin{array}{l}\text { Clinical pharmacy operations for } \\
\text { community pharmacy chain }\end{array}$ & $\begin{array}{l}\text { Large UK community pharmacy } \\
\text { chain }\end{array}$ \\
\hline
\end{tabular}

Focus group 1

\begin{tabular}{|c|c|c|}
\hline A & Medicines management technician & City centre teaching hospital \\
\hline B & $\begin{array}{l}\text { AMU medicines management } \\
\text { technician }\end{array}$ & City centre teaching hospital \\
\hline C & $\begin{array}{l}\text { Lead medicines management } \\
\text { technician }\end{array}$ & City centre teaching hospital \\
\hline D & Medicines management technician & City centre teaching hospital \\
\hline $\mathrm{E}$ & $\begin{array}{l}\text { Renal medicines management } \\
\text { technician }\end{array}$ & City centre teaching hospital \\
\hline $\mathrm{F}$ & Medicines management technician & City centre teaching hospital \\
\hline G & Medicines management technician & City centre teaching hospital \\
\hline \multicolumn{3}{|c|}{ Focus group 2} \\
\hline $\mathrm{H}$ & Patient representative & $\begin{array}{l}\text { Patient and public involvement } \\
\text { group North West }\end{array}$ \\
\hline I & Dementia nurse lead & $\begin{array}{l}\text { Patient and public involvemen } \\
\text { group North West }\end{array}$ \\
\hline J & $\begin{array}{l}\text { Learning disabilities nurse/carer } \\
\text { representative }\end{array}$ & $\begin{array}{l}\text { Patient and public involvement } \\
\text { group North West }\end{array}$ \\
\hline K & Patient representative & $\begin{array}{l}\text { Patient and public involvement } \\
\text { group North West }\end{array}$ \\
\hline L & Patient representative & $\begin{array}{l}\text { Patient and public involvemen } \\
\text { group North West }\end{array}$ \\
\hline M & Carer representative & $\begin{array}{l}\text { Patient and public involvement } \\
\text { group North West }\end{array}$ \\
\hline $\mathrm{N}$ & Patient representative & $\begin{array}{l}\text { Patient and public involvemen } \\
\text { group North West }\end{array}$ \\
\hline
\end{tabular}

$\mathrm{AMU}$, acute medical unit; GP, general practitioner.

discharge prescriptions for patients immediately during a busy ward round. This would differ depending on the individual ward round. Second, it may be difficult to obtain a timely supply of discharge medication from the community pharmacy. This would depend on time of discharge, community pharmacy opening hours, availability of medication at the community pharmacy and a delivery service. Individual cases would have to be worked through and communication between the hospital and community pharmacy would be essential to ensure patients received their medication.

The new MOC focuses on the supply of medication for discharge. A risk was highlighted that if patients receive their medication faster, other causes of delay to discharge could become apparent.

I think the waits for other things are still going to be there. Medicines are often used as the excuse. What it might mean is that other delays could become more apparent, because if they've got their medicines then you know they are waiting for something else.

(Medicines safety and care of the elderly pharmacist)

By implementing the new MOC, other important processes at discharge should not be overlooked as a result, such as social care issues and writing discharge summaries.

\section{Impact on education}

Participants discussed the impact of the new MOC on improved education for healthcare professionals due to improved teamworking and collaboration. For example, more support could be provided for junior pharmacists on wards, improved education on prescribing issues for doctors of all levels of experience and upskilling community pharmacists to allow them to perform more clinically orientated roles.

Participants raised the issue of potentially deskilling doctors by removing the task of writing discharge prescriptions. All participants recognised this risk, but the majority felt that it was not their sole opportunity to prescribe and by ensuring that the pharmacists write discharge prescriptions based on prescribing decisions made on the ward round with the integrated team, this could benefit the doctors.

\section{Resources required to implement the new MOC}

Participants felt that the new MOC would be feasible if the appropriate resources were in place.

\section{Infrastructure}

Embedding the appropriate infrastructure is important for the success of the new MOC. Two main aspects were highlighted by participants: the human infrastructure, in terms of staffing levels and integrated ward teams, and also having the appropriate technology functioning efficiently to allow the new MOC to run.

Adequate staffing was considered essential to enable pharmacists to safely carry out their new role. Participants noted that sufficient staffing levels to provide the new MOC may not be achievable in every hospital due to their sizes and budgets. This could impact pharmacy workload. One concern was that if pharmacy teams were understaffed, the cause of delay to discharge could shift entirely to the pharmacists, without any benefit to patients. One suggestion by participants to achieve the required staffing levels was to redistribute current roles within the pharmacy team. Upskilling staff at each level to undertake roles traditionally carried out by a pharmacist could free pharmacist time for new roles.

If we're losing dispensing activity should we lose posts? Or can we redistribute those posts? It's about how we are reconfiguring the workforce to get the most benefit and utilisation. (Clinical pharmacy services manager) 


\section{Training}

Most participants perceived that the new MOC uses community pharmacists' existing skills, therefore minimising the need for additional training. However, other participants suggested that community pharmacists may require further clinical training to provide an understanding of the discharge prescription and the medication they are likely to be dispensing. Additionally, if a new electronic system was to be introduced, training would be required to ensure staff could access and use the system to guarantee that discharge prescriptions could be actioned.

\section{Preplanning required before implementation}

Participants suggested that arrangements may be required before implementation. For example, the legality of community pharmacists dispensing discharge prescriptions requires review prior to implementation.

Furthermore, to ensure that the discharge prescriptions received by community pharmacies are seen as urgent and important, community pharmacists should be made aware of the new MOC. One participant suggested that the new MOC be commissioned as a service by clinical commissioning groups. As a commissioned service, community pharmacists may be more familiar with the process and understand the urgency when they receive a discharge prescription.

\section{Ensuring quality and safety of the new MOC}

Participants highlighted several areas that would need to be appropriately managed to ensure the new MOC provided quality and safe patient care.

\section{Quality and safety issues}

In the new MOC, the hospital pharmacy team are responsible for roles traditionally performed by doctors or nurses. This includes writing discharge prescriptions and handing medication to the patient at the point of discharge. Participants felt that to drive quality and efficiency, the pharmacy team were appropriate specialists to carry out these roles.

The risk of a safety issue was highlighted with patients potentially receiving medication from a variety of sources. This could lead to confusion and potentially patient harm. Communication with the patient and community pharmacy is essential to explain the process to reduce patient risk.

Several participants noted their concerns about the potential for patients not receiving their medication as a result of this new MOC. The logistical issues highlighted as potential barriers to patients receiving their discharge medication are discussed within the 'addressing delays at discharge' section.

The difficulty is you are sending [patients] out on the premise that they get those medicines that day. And there are lots of unknown factors that can prevent that from happening. There are lots of things that can prevent the patient from getting the medicine that you would have definitely given them. (Community pharmacist)

Participants thought that a fail-safe mechanism should be integral to the MOC to guarantee that patients receive their discharge medication.

\section{Managing patient expectations}

Views were mixed over whether patients would be happy to receive their medication from their community pharmacy. Whereas some participants thought that patients would be happy that they did not have to wait, others felt that patients would assume the hospital should supply their medication. The patient and carer representatives were positive about the change and felt that it would improve the experience, particularly those with previous poor experience of obtaining their discharge medication from hospital.

It would be much better. I had to come back at 8 o'clock at night to get my medicines, in the dark. They didn't light the car park and there was all kinds of people hovering outside the hospital. So for me a community pharmacy would be so much better. (Patient representative)

Numerous countries across Europe currently discharge patients from hospital with a prescription to obtain from a community pharmacy as standard. Patients do not receive discharge medication from the hospital and this is a well-accepted system.

\section{Healthcare professional competence}

Participants felt that the pharmacist writing the discharge prescription should be a non-medical prescriber (NMP) familiar with the clinical area that they are prescribing in and ideally familiar with the patients that they are prescribing for. One participant highlighted that just because a pharmacist is a qualified NMP does not automatically mean that they will be confident to carry out that role. Experience is needed to build confidence and feel comfortable writing discharge prescriptions.

\section{Prescribing responsibility}

Currently, the responsibility of the discharge prescription lies with the doctor. Participants debated who should be responsible for this in the new MOC. Prescribing responsibility becomes a particular issue if the pharmacist writing the discharge prescription disagrees with the doctor's prescribing choices. It was suggested that the responsibility should be with the consultant and the team responsible for the patient.

Participants had mixed opinions over whether writing discharge prescriptions should be classed as transcribing rather than prescribing, as the discharge prescription is based on the medications prescribed on the inpatient chart.

\section{DISCUSSION}

Today's NHS faces a range of challenges. The population is ageing and there is a significant increase in the number of people with long-term conditions requiring health and social care. ${ }^{30}$ Additionally, the NHS is under a huge financial pressure due to a lack of funding. This is a timely study, as the NHS is in the midst of a changing care environment. Many changes to the way that care is delivered are under way, which is essential to provide quality care for all patients, within the restraints of the limited resources available. This means a radical change from current ways of working. The study approach taken-to develop a new MOC to improve patient discharge-supports the current agenda as NHS England's Five Year Forward View suggested that new models of care are required to improve care and deliver care closer to patients through integrated care models. ${ }^{31}$

The potential impact of this research is wide reaching. A seamless discharge process that will provide timely and safe transfer for patients could lead to many implications for practice. As well as improving patient flow through the hospital, the MOC could potentially lower hospital readmission rates by reducing medication errors that put patients at higher risk of harm and readmission. Additionally, a reduction in medication waste could be seen, as only appropriate supplies of medication will be provided.

Moving patient's care from hospital into the community is a priority in the UK and internationally. ${ }^{32} 33$ The consensus is that 
as much care as possible should be delivered in a local, more convenient setting for patients. This is to improve patient experience and reduce the burden on the NHS by removing the focus from treating patients at expensive hospitals. ${ }^{32}$ The new MOC encourages the provision of patient care in the community and advertises the ongoing support that they can receive from their community pharmacist, as many patients are unaware of the services available.

\section{Limitations and further work}

As with all qualitative research, a limitation was the inherent risk of personal bias from the researcher because of their role as a hospital pharmacist. In an attempt to reduce this risk, all analyses were grounded in the data. Despite the diverse range of participants involved in the study, a limited sample was used. As a result, the findings are not generalisable.

A further limitation to this study was the different methods of data collection used. Participants were busy and would have been difficult to recruit if focus groups were the only option. A limited number of focus groups were carried out and therefore could not be repeated. If the study were to be repeated, one method of data collection would be appropriate.

Further work will involve a full evaluation of the new MOC following a pilot study. During the pilot study, participants' suggestions from this study will be used during implementation and evaluation to ensure the success of the new MOC.

\section{CONCLUSION}

This study provided a formative evaluation of the proposed new MOC for medication supply at patient discharge. Overall, stakeholders were enthusiastic about the proposed model and had many positive comments. The new MOC was therefore considered feasible and acceptable by the target population.

The findings have identified which areas of the new MOC stakeholders thought would work well and where problems may arise. Logistical issues were highlighted, mainly within two areas: pharmacists having the time to write discharge prescriptions during the ward round and the logistical issues of community pharmacists supplying discharge medication. Many of the participants suggested a variety of solutions to such problems. The knowledge, skills and resources required to deliver the new MOC were established. This study has been essential to provide feedback on the proposed new MOC which is now at a suitable stage to pilot.

\section{What this paper adds}

What is already known on this subject

- Issues such as delays to discharge and medication problems often arise after hospital discharge which can result in poor experience, patient harm and hospital readmission.

- It is important to improve patient discharge by developing new models of care to provide quality, efficient patient care.

\section{What this study adds}

- An innovative model of care was developed, involving community pharmacists in the supply of medication for patients at hospital discharge.

- This formative evaluation has concluded that the proposed new model of care was considered feasible and acceptable by relevant stakeholders and is ready to pilot.
Contributors The study was carried out and this manuscript written by the main author SW as part of her PhD study. Support and guidance throughout the study and writing of the manuscript were provided by the supervisory team (CWM, RM and $A B E)$ who are listed in order of the amount of contribution.

Funding The authors have not declared a specific grant for this research from any funding agency in the public, commercial or not-for-profit sectors.

Competing interests None declared.

Ethics approval Liverpool John Moores University Research Ethics Committee.

Provenance and peer review Not commissioned; externally peer reviewed.

(C) European Association of Hospital Pharmacists (unless otherwise stated in the text of the article) 2019. All rights reserved. No commercial use is permitted unless otherwise expressly granted.

\section{REFERENCES}

1 NHS England. Putting patients first, NHS England Business plan 2013/14- 2014/15, 2013.

2 BMA Patient Liason Group. Hospital discharge : the patient. carer and doctor perspective 2014

3 Gross Z. How pharmacists help speed up the discharge process to release beds. Pharm J 2001:267:673-4.

4 Coleman EA, Smith JD, Raha D, et al. Posthospital Medication Discrepancies. Arch Intern Med 2005;165:1842-7.

5 Witherington EM, Pirzada OM, Avery AJ. Communication gaps and readmissions to hospital for patients aged 75 years and older: observational study. Qual Saf Health Care 2008:17:71-5.

6 Bullock S, Morecroft CW, Mullen R, et al. Hospital patient discharge process: an evaluation. Eur J Hosp Pharm 2017;24:278-82.

7 Parliamentary and Health Service Ombudsman. A report of investigations into unsafe discharge from hospital, 2016.

8 Royal Pharmaceutical Society of Great Britain, The Guild of Hospital Pharmacists, The Pharmaceutical Services Negotiating Committee, The Primary Care Pharmacists Association. Moving patients, moving medicines, moving safely, 2006

9 Health \& Social Care Joint Unit and Change Agents Team. Discharge from hospital: pathway, process and practice. London, 2003.

10 Hammad EA, Bhattacharya D, Walton C, et al. Communication of clinical information upon hospital discharge: a regional audit. Int J Pharm Pract 2012;20:21-2.

11 Sharma A, Black L. Hospital prescribing - getting discharge summaries right [Internet]. GPonline.com. 2011 http://www.gponline.com/News/article/1067582/HospitalPrescribing-Getting-discharge-summaries-right/

12 Arora VM, Prochaska ML, Farnan JM, et al. Problems after discharge and understanding of communication with their primary care physicians among hospitalized seniors: a mixed methods study. J Hosp Med 2010:5:385-91.

13 Ziaeian B, Araujo KL, Van Ness PH, et al. Medication reconciliation accuracy and patient understanding of intended medication changes on hospital discharge. J Gen Intern Med 2012;27:1513-20.

14 Society of Hospital Medicine. Better outcomes by optimising safe transitions [Internet]. $2014 \mathrm{http} / / / \mathrm{ww} w$.hospitalmedicine.org/Web/Quality_Innovation/ Implementation_Toolkits/Project_BOOST/Web/Quality_Innovation/ Implementation_Toolkit/Boost/Overview.aspx?hkey=09496d80-8dae-4790-af72efed8c3e3161

15 Agency for Healthcare Research and Quality. Project RED (Re-Engineered Discharge) Training Program [Internet]. http://www.ahrq.gov/professionals/systems/hospital/red/ index.html

16 Cynosure Health, California Quality Collaborative. Avoid Readmissions through Collaboration (ARC) [Internet]. 2013 http://www.avoidreadmissions.com/about-arc. html

17 Delisle DR. Care transitions programs: a review of hospital-based programs targeted to reduce readmissions. Prof Case Manag 2013;18:273-83.

18 Gleason KM, McDaniel MR, Feinglass J, et al. Results of the Medications at Transitions and Clinical Handoffs (MATCH) study: an analysis of medication reconciliation errors and risk factors at hospital admission. J Gen Intern Med 2010;25:441-7.

19 Kutryba B, Dudzik-Urbaniak E, Göbel A, et al. The European Handover project [Internet]. $2011 \mathrm{http}: / /$ handover.eu/deliverables.html

20 Rahman MH, Green CF, Armstrong DJ. An evaluation of pharmacist-written hospital discharge prescriptions on general surgical wards. Int J Pharm Pract 2005;13:179-85

21 Craig A. The benefits of a Discharge Prescription improvement programme [Internet]. 2015 http://nhsscotlandevent.com/sites/default/files/2016 - NHSScotland Event Posters - VS03 - proofed - May 2016.pdf

22 Royal S, Smeaton L, Avery AJ, et al. Interventions in primary care to reduce medication related adverse events and hospital admissions: systematic review and meta-analysis. Qual Saf Health Care 2006;15:23-31.

23 Harrington AR, Calabro K, Boesen K, et al. Development and evaluation of a postdischarge medication reconciliation program. Value in health. 2014;17:A152-3015. 
24 Nazar H, Nazar Z, Portlock J, et al. A systematic review of the role of community pharmacies in improving the transition from secondary to primary care. $\mathrm{Br} J \mathrm{Clin}$ Pharmacol 2015;80:936-48.

25 Duggan B, Ryder SA. Community pharmacy services at the primary-secondary care interface. Int J Clin Pharmacy 2012;34:211-2.

26 Cavrenne P, Spinewine A. Hospital discharge: Is information transfer from the hospital pharmacist to the community pharmacist useful? Farm Tijdschr voor Belgie 2008;85:78-83.

27 Nazar $\mathrm{H}$, Brice $\mathrm{S}$, Akhter $\mathrm{N}$, et al. New transfer of care initiative of electronic referral from hospital to community pharmacy in England: a formative service evaluation. BMJ Open 2016;6:e012532

28 Clark C. Transfer of care: how electronic referral systems can help to keep patients safe. Pharm J 2016;297 http://www.pharmaceutical-journal.com/news-and- analysis/features/transfer-of-care-how-electronic-referral-systems-can-help-tokeep-patients-safe/20201492.article

29 Wright S, Morecroft CW, Mullen R, et al. UK hospital patient discharge: the patient perspective. Eur J Hosp Pharm 2017;24:338-42.

30 NHS England. The NHS belongs to the people: a call to action. London, 2013

31 NHS England, Care Quality Commission, Health Education England, Monitor, Public Health England TDA. Five Year Forward View. 2014 https://www.england.nhs.uk/wpcontent/uploads/2014/10/5yfv-web.pdf

32 Department of Health. Our health, our care, our say: London, 2006.

33 Nursing RC, Royal College of Nursing. Moving care to the community: an international perspective, 2013. 